\title{
Conformers of diheteroaryl ketones and thioketones: a quantum chemical study of their properties and fundamental intramolecular energetic effects
}

\author{
Piotr Matczak ${ }^{1} \cdot$ Małgorzata Domagała $^{1} \cdot$ Sławomir Domagała $^{2}$
}

Received: 22 June 2015 / Accepted: 14 July 2015/Published online: 4 August 2015

(C) The Author(s) 2015. This article is published with open access at Springerlink.com

\begin{abstract}
The conformational behavior of ten diheteroaryl ketones and thioketones is investigated using various quantum chemical methods. These ketones and thioketones are formed by the disubstitution of formaldehyde and thioformaldehyde with such a heteroaryl group as 2 -furanyl, 2-thiophenyl, 2-selenophenyl, 2-pyrrolyl or 1-methyl-2-pyrrolyl. For these compounds, their conformational preference and the energetic ordering of their conformers are determined at the MP2 and B3LYP levels of theory. Energetic barriers resulting from the interconversion between conformations are also estimated. The natural bond orbital (NBO) and interacting quantum atoms (IQA) methods are used to study fundamental intramolecular energetic effects influencing the stability of individual conformers. The results of the two methods indicate the great significance of the effect associated with electron delocalization (in the form of either NBO donor-acceptor interactions or the IQA interatomic exchange-correlation interaction energy) in governing the conformational behavior of the investigated diheteroaryl ketones and thioketones.
\end{abstract}

Electronic supplementary material The online version of this article (doi:10.1007/s11224-015-0643-3) contains supplementary material, which is available to authorized users.

Piotr Matczak

p.a.matczak@gmail.com

1 Department of Theoretical and Structural Chemistry, Faculty of Chemistry, University of Łódź, Pomorska 163/165, 90-236 Lodz, Poland

2 Department of Inorganic and Analytical Chemistry, Faculty of Chemistry, University of Łódź, Tamka 12, 91-403 Lodz, Poland
Keywords Diheteroaryl ketones · Diheteroaryl thioketones · Conformation · Quantum chemical calculations

\section{Introduction}

Chemical compounds exhibit many physical, chemical and biological properties that are closely related to the molecular structure of the compounds. The molecular structure of a chemical compound is characterized by the spatial arrangement of atoms in the molecules of this compound and by the bonds holding together atoms in the molecules. For some compounds, it is possible to change the spatial arrangement of atoms in their molecules by rotations about formally single bonds. In consequence, conformational isomerism is observed for such compounds, which means that the different molecular geometries of a given chemical compound, that is, its conformers, can be interconverted exclusively by rotations about formally single bonds $[1,2]$. Interestingly, different conformers may possess quite distinct properties [3-5], and therefore, investigating the conformational behavior of chemical compounds is important from a practical point of view. From a more fundamental standpoint, the information about the preferred conformer of a given compound is helpful in understanding the intramolecular forces governing the conformational behavior of this compound [6-8].

In this work, the conformation of ten diheteroaryl ketones and thioketones is studied using a variety of quantum chemical methods. We focus on formaldehyde and thioformaldehyde disubstituted with such a fivemembered heteroaryl group as 2-furanyl, 2-thiophenyl, 2-selenophenyl, 2-pyrrolyl or 1-methyl-2-pyrrolyl. Part of the compounds considered here have been synthesized only 
recently [9]. The structure of the investigated diheteroaryl ketones 1a-5a is sketched in Scheme 1. This scheme also represents the corresponding diheteroaryl thioketones $\mathbf{1 b}-$ $\mathbf{5 b}$ if $\mathrm{Y}=\mathrm{S}$ is assumed. For compounds $\mathbf{1 a}-\mathbf{5 a}$ and $\mathbf{1 b}-\mathbf{5 b}$, the occurrence of conformational isomerism in their molecules results from the rotations of the whole heteroaryl substituents about the single bonds between these substituents and the carbon atom of (thio)carbonyl group. Both for $\mathbf{1 a}-\mathbf{5 a}$ and for $\mathbf{1 b}-\mathbf{5 b}$, it is possible to distinguish four characteristic rotatory conformations, depending on the relative orientation of the $\mathrm{Y}$ atom and the heteroatoms present in $X$. Three of the conformations are shown in Scheme 1. The $\mathrm{X}, \mathrm{Y}$-cis orientations for $\mathrm{X}$ in both heteroaryl substituents yield the conformation denoted by $c c$ in the scheme. The occurrence of the X,Y-cis orientation for $\mathrm{X}$ belonging to one substituent, together with the $\mathrm{X}, \mathrm{Y}$-trans orientation involving $\mathrm{X}$ from another heteroaryl substituent, leads to the mixed conformation, marked by the abbreviation $c t$ in Scheme 1. Because 1a-5a and 1b-5b possess two identical heteroaryl substituents, we consider the other mixed conformer, that is, the $t c$-one, to be equivalent to the $c t$-conformer for the purposes of the present study. Finally, the X,Y-trans orientations found for $\mathrm{X}$ in both heteroaryl substituents refer to the $t t$ conformation.

For some of the diheteroaryl ketones and thioketones considered here, their conformational behavior has previously been studied experimentally [10-13]. From dipole moment measurements, it is inferred that the $c c$-conformation is preferred for 2a [10]. A more recent analysis of the dipole moments of $\mathbf{2 a}$ and $\mathbf{2} \mathbf{b}$ in benzene solutions suggests a mixture of $c c$-conformer and mixed conformers, with the former being more abundant (72 and $91 \%$ for $\mathbf{2 a}$ and $\mathbf{2} \mathbf{b}$, respectively) [11]. In the case of $\mathbf{1 a}$ in benzene solution, its dipole moment is consistent with a mixture of $c c$-conformer and mixed conformers, with the latter being more abundant (73\%) [11]. Dipole moment measurements also show that the molecules of $\mathbf{4 a}$ and $\mathbf{4 b}$ tend to adopt the $c c$-conformation in several nonpolar solvents [12]. The $\mathrm{X}$-ray analysis of crystal 2a indicates that the $\mathrm{S}$ atoms are always on the same side of the carbonyl group, and therefore, the $c c$-conformer of $\mathbf{2 a}$ seems to display an attractive interaction between sulfur and oxygen [13]. Results from NMR spectra and lanthanide-induced shift measurements suggest that the O,O-trans orientation is largely preferred for 1a in chloroform solution [13]. No definite conclusion on the preference of the $t t$-conformer relative to the $c t$-one can, however, be reached from the lanthanide-induced shift measurements for 1a. The coexistence of various conformers also shows that the energy difference between the $c t$ - and $t t$-conformers is relatively small for 1a. In addition, the conformational behavior of 1a in solution is expected to be dependent on the solvent applied and the $c t$-conformer is likely to become more stable in solvents of increasing polarity [13].

Molecular properties of various diheteroaryl ketones and thioketones have previously been investigated using theoretical methods [13-19]. In particular, the conformational behavior of such compounds has been the subject of many theoretical investigations because theoretical methods are an effective tool for detecting different conformers and determining their relative stabilities. The results of quantum chemical conformational analysis have so far been reported only for a small part of the compounds considered in this work. The results of early quantum chemical calculations performed at the HF/3-21G level of theory indicate that for $\mathbf{1 a}$ its $c t$-conformer is slightly more stable than the $t t$-conformer, while the $c c$-conformer turns out to be the least stable in the gas phase [13]. For the conformations of 2a, the ordering of relative energies calculated at the HF/3$21 \mathrm{G}^{*}$ level follows $c c<c t<t t$ [13]. On the one hand, the prevalence of the $c c$-conformer for $\mathbf{2 a}$ is confirmed by the results of calculations carried out using MP2/6-311G** [15], but, on the other hand, the most recent B3LYP/ $6-311 \mathrm{G}^{*}$ calculation designates the $c t$-conformer as the global energy minimum [18]. In the above-mentioned

Scheme 1 Skeletal structural formulas of the investigated diheteroaryl ketones and thioketones in their three conformations

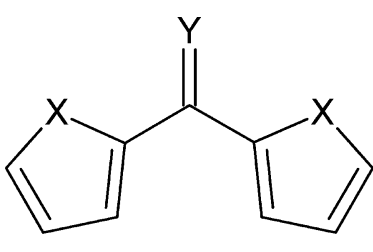

CC

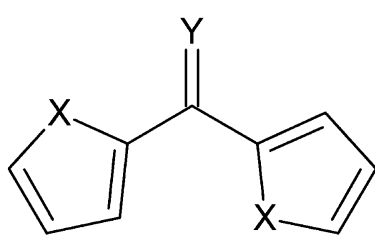

$c t$<smiles></smiles>

$t t$ 1a: $X=O ; Y=O$

2a: $X=S ; Y=O$

3a: $X=\mathrm{Se} ; Y=\mathrm{O}$

4a: $X=\mathrm{N}-\mathrm{H} ; \mathrm{Y}=\mathrm{O}$

5a: $X=N-M e ; Y=O$ 1b: $X=O ; Y=S$

2b: $X=S ; Y=S$

3b: $X=\mathrm{Se} ; Y=S$

4b: $X=\mathrm{N}-\mathrm{H} ; Y=\mathrm{S}$

5b: $X=\mathrm{N}-\mathrm{Me} ; \mathrm{Y}=\mathrm{S}$ 
theoretical investigations, the conformational behavior of 1a and 2a is characterized by specifying the molecular geometries, relative energies and dipole moments of conformers.

In the present work, we start with providing the geometrical and energetic description of the conformations occurring in $\mathbf{1 a}-\mathbf{5 a}$ and $\mathbf{1 b}-\mathbf{5 b}$. Standard wave function theory (WFT) and density functional theory (DFT) methods are used for this routine description. Next, we extend the analysis of the conformational behavior of the compounds in question and two quantum chemical methods with great interpretative potential, namely the natural bond order (NBO) analysis and the interacting quantum atoms (IQA) method, are employed to explain the conformational behavior from different perspectives. It is of great interest for us to establish whether these methods yield a consistent view of the conformational behavior of $\mathbf{1 a}-\mathbf{5 a}$ and $\mathbf{1 b}-\mathbf{5 b}$. The fundamental intramolecular energetic effects that play stabilizing and destabilizing roles in individual conformations are also characterized in detail.

\section{Computational details}

The geometries of three gas-phase conformers for $\mathbf{1 a - 5 a}$ and $\mathbf{1 b}-\mathbf{5 b}$ in their ground electron states have been optimized at the WFT level using the Møller-Plesset secondorder perturbation theory (MP2) $[20,21]$ and at the DFT level using Becke's three-parameter global hybrid density functional with the Vosko-Wilk-Nusair V local correlation and the Lee-Yang-Parr non-local correlation part (B3LYP) [22-24]. The def2-TZVP basis set [25] has been assigned to the atoms of all conformers optimized by MP2, whereas the B3LYP method has been combined with both def2TZVP and def2-QZVPP [25]. For selected compounds, additional calculations have been carried out using B3LYP with Grimme's dispersion corrections (DFT-D) [26-28], MP2, SCS-MP2 [29], CCSD [30] and CCSD(T) [30]. These calculations involve the def2-QZVPP basis set. All WFT calculations take advantage of the resolution of the identity approximation [31]. The optimized geometries of all conformers have been confirmed to be local minima on the potential energy surface by calculating harmonic vibrational normal modes. All WFT and DFT calculations are done with TURBOMOLE 6.3.1 and 6.6 [32].

The wave functions of all conformers optimized at the B3LYP/def2-QZVPP level of theory are used for the NBO [33] and IQA [34] analyses. The NBO calculations have been carried out with the NBO 6.0 program [35], whereas the IQA calculations make use of the implementation available in AIMALL 14.06.21 [36]. NBO archive files (*.47) and AIM extended wave function files (*.wfx) required by the above-mentioned programs have been generated by GAUSSIAN 09 D.01 [37].

\section{Results and discussion}

\section{Relative energies}

Let us begin the analysis of the conformational behavior of $\mathbf{1 a}-\mathbf{5 a}$ and $\mathbf{1 b}-\mathbf{5 b}$ with establishing the energetic preference of individual conformations. For each compound, the sequence of its three conformations is ordered with respect to increasing energy and then the energy of each conformation in the sequence is calculated relative to the energy of the preferred conformation, that is, the lowest energy one. The energy of each conformer is expressed as its total electron energy $E$ and its Gibbs free energy $G$ at $298.15 \mathrm{~K}$. The former does not include the zero-point vibrational energy. For the preferred conformation, its relative energies $\Delta E$ and $\Delta G$ are obviously equal to zero, whereas less energetically favorable conformations exhibit positive values of $\Delta E$ and $\Delta G$. The values of $\Delta E$ and $\Delta G$ for ketones $\mathbf{1 a}-\mathbf{5 a}$ and thioketones $\mathbf{1 b}-\mathbf{5 b}$ in three conformations are listed in Tables 1 and 2. The tabulated results have been obtained from MP2/def2-TZVP and B3LYP/ def2-QZVPP. Calculations at the B3LYP/def2-TZVP level have also been carried out, but they do not give any new insights over those of B3LYP/def2-QZVPP; therefore, they are not presented and discussed in this section (the results of the B3LYP/def2-TZVP calculations can be found in Tables S1 and S2, see Electronic Supplementary Material).

It is evident that there is no single conformation that is preferred for the whole set of investigated compounds. Both energetic criteria, that is, $\Delta E$ and $\Delta G$, indicate that the $c t$-conformation is most favorable for $\mathbf{1 a}$ and $\mathbf{1 b}$, while the $c c$-conformation is designated as the preferred one for the remaining compounds. The preference of the $c t$-conformation detected in this work for 1a and the preference of the $c c$-conformation for $\mathbf{2} \mathbf{a}$ agree with the findings reported in two previous theoretical investigations of these compounds $[13,15]$.

Three conformations found for $\mathbf{1 a}$ can be ordered in the following sequence $c t<t t<c c$ with respect to the growing values of $\Delta E$ and $\Delta G$. The same is observed for $\mathbf{1 b}$, although the $\Delta E$ criterion obtained from the MP2/def2TZVP method predicts that the $t t$-conformation is less favorable than the $c c$-conformation. In this case, the difference between the $\Delta E$ values of these two conformations is, however, very small and, what is more important, the ordering is corrected when the $\Delta G$ values are considered. We will return to the issue of the quality of the MP2/def2TZVP results further in this section. For $\mathbf{2 a}-\mathbf{5 a}$ and $\mathbf{2} \mathbf{b}-\mathbf{5} \mathbf{b}$, the increases in $\Delta E$ and $\Delta G$ follow the ordering 
Table 1 Some selected energetic $(\Delta E$ and $\Delta G$ in $\mathrm{kcal} / \mathrm{mol})$ and structural $\left(\tau_{1}\right.$ and $\tau_{2}$ in $^{\circ}$ ) parameters calculated for three conformations of $\mathbf{1 a}-$ 5a

\begin{tabular}{|c|c|c|c|c|c|c|c|c|c|c|}
\hline \multirow[t]{2}{*}{ Conformer } & \multicolumn{5}{|c|}{ MP2/def2-TZVP } & \multicolumn{5}{|c|}{ B3LYP/def2-QZVPP } \\
\hline & $\Delta E$ & $\Delta G$ & $P$ & $\tau_{1}$ & $\tau_{2}$ & $\Delta E$ & $\Delta G$ & $P$ & $\tau_{1}$ & $\tau_{2}$ \\
\hline$c c-\mathbf{1 a}$ & 1.24 & 2.73 & 1 & -19.1 & -19.1 & 2.14 & 2.84 & 1 & -17.7 & -17.7 \\
\hline$c t-\mathbf{1 a}$ & 0.00 & 0.00 & 80 & 0.0 & 180.0 & 0.00 & 0.00 & 67 & -0.1 & 179.9 \\
\hline$t t-\mathbf{1 a}$ & 0.51 & 0.84 & 19 & 180.0 & 180.0 & 0.34 & 0.44 & 32 & 180.0 & 180.0 \\
\hline$c c-\mathbf{2 a}$ & 0.00 & 0.00 & 55 & -20.5 & -20.5 & 0.00 & 0.00 & 55 & -18.6 & -18.6 \\
\hline$c t-\mathbf{2 a}$ & 0.83 & 0.21 & 39 & -20.4 & 156.2 & 0.77 & 0.17 & 41 & -15.9 & 157.9 \\
\hline$t t-\mathbf{2 a}$ & 1.58 & 1.28 & 6 & 156.8 & 156.8 & 1.85 & 1.56 & 4 & 159.2 & 159.2 \\
\hline$c c-\mathbf{3 a}$ & 0.00 & 0.00 & 71 & -20.1 & -20.1 & 0.00 & 0.00 & 80 & -18.1 & -18.1 \\
\hline$c t-\mathbf{3 a}$ & 1.22 & 0.61 & 26 & -20.6 & 153.8 & 1.41 & 0.84 & 19 & -16.0 & 154.6 \\
\hline$t t-\mathbf{3 a}$ & 2.15 & 1.90 & 3 & 154.5 & 154.5 & 2.93 & 2.73 & 1 & 155.9 & 155.9 \\
\hline$c c-\mathbf{4 a}$ & 0.00 & 0.00 & 99 & -10.5 & -10.5 & 0.00 & 0.00 & 100 & -4.9 & -4.9 \\
\hline$c t-\mathbf{4 a}$ & 3.20 & 2.91 & 1 & -15.5 & 159.7 & 3.82 & 3.69 & 0 & -12.6 & 161.8 \\
\hline$t t-\mathbf{4 a}$ & 8.09 & 7.91 & 0 & 154.4 & 154.4 & 8.99 & 8.94 & 0 & 156.4 & 156.4 \\
\hline$c c-\mathbf{5 a}$ & 0.00 & 0.00 & 100 & -21.0 & -21.0 & 0.00 & 0.00 & 100 & -19.7 & -19.7 \\
\hline$c t-\mathbf{5 a}$ & 4.54 & 3.42 & 0 & -19.3 & 143.3 & 5.37 & 4.35 & 0 & -17.5 & 142.5 \\
\hline$t t-\mathbf{5 a}$ & 6.36 & 5.33 & 0 & 143.4 & 143.4 & 9.63 & 6.89 & 0 & 143.1 & 143.1 \\
\hline
\end{tabular}

Populations of individual conformers $(P$ in $\%)$ are also tabulated

\begin{tabular}{|c|c|c|c|c|c|c|c|c|c|c|}
\hline \multirow[t]{2}{*}{ Conformer } & \multicolumn{5}{|c|}{ MP2/def2-TZVP } & \multicolumn{5}{|c|}{ B3LYP/def2-QZVPP } \\
\hline & $\Delta E$ & $\Delta G$ & $P$ & $\tau_{1}$ & $\tau_{2}$ & $\Delta E$ & $\Delta G$ & $P$ & $\tau_{1}$ & $\tau_{2}$ \\
\hline$c c-\mathbf{1 b}$ & 0.49 & 1.22 & 9 & -22.0 & -22.0 & 1.46 & 2.58 & 1 & -21.4 & -21.4 \\
\hline$c t-\mathbf{1 b}$ & 0.00 & 0.00 & 74 & -13.0 & 163.8 & 0.00 & 0.00 & 82 & -6.4 & 172.5 \\
\hline$t t-\mathbf{1 b}$ & 0.55 & 0.88 & 17 & 160.1 & 160.1 & 0.31 & 0.92 & 17 & 164.5 & 164.5 \\
\hline$c c-\mathbf{2 b}$ & 0.00 & 0.00 & 69 & -24.0 & -24.0 & 0.00 & 0.00 & 65 & -22.8 & -22.8 \\
\hline$c t-\mathbf{2} \mathbf{b}$ & 1.13 & 0.52 & 28 & -25.3 & 150.0 & 0.99 & 0.42 & 32 & -21.5 & 149.7 \\
\hline$t t-2 \mathbf{b}$ & 2.24 & 1.91 & 3 & 149.5 & 149.5 & 2.22 & 1.92 & 3 & 150.6 & 150.6 \\
\hline$c c-\mathbf{3 b}$ & 0.00 & 0.00 & 77 & -23.6 & -23.6 & 0.00 & 0.00 & 80 & -22.2 & -22.2 \\
\hline$c t-\mathbf{3 b}$ & 1.37 & 0.75 & 22 & -24.8 & 147.8 & 1.44 & 0.85 & 19 & -19.9 & 146.3 \\
\hline$t t-\mathbf{3 b}$ & 2.62 & 2.29 & 1 & 148.0 & 148.0 & 3.00 & 2.71 & 1 & 148.9 & 148.9 \\
\hline$c c-\mathbf{4 b}$ & 0.00 & 0.00 & 99 & -15.9 & -15.9 & 0.00 & 0.00 & 100 & -13.9 & -13.9 \\
\hline$c t-\mathbf{4 b}$ & 3.37 & 2.94 & 1 & -17.7 & 155.9 & 3.92 & 3.40 & 0 & -15.3 & 157.3 \\
\hline$t t-\mathbf{4} \mathbf{b}$ & 8.54 & 8.21 & 0 & 152.2 & 152.2 & 9.41 & 8.91 & 0 & 154.0 & 154.0 \\
\hline$c c-\mathbf{5 b}$ & 0.00 & 0.00 & 77 & -27.9 & -27.9 & 0.00 & 0.00 & 97 & -27.8 & -27.8 \\
\hline$c t-\mathbf{5} \mathbf{b}$ & 2.05 & 1.05 & 13 & -29.6 & 142.9 & 3.05 & 1.99 & 3 & -27.6 & 142.0 \\
\hline$t t-\mathbf{5 b}$ & 2.01 & 1.22 & 10 & 142.7 & 142.7 & 5.04 & 3.81 & 0 & 142.0 & 142.0 \\
\hline
\end{tabular}

Populations of individual conformers $(P$ in $\%)$ are also tabulated
Table 2 Some selected energetic $(\Delta E$ and $\Delta G$ in $\mathrm{kcal} / \mathrm{mol})$ and structural $\left(\tau_{1}\right.$ and $\tau_{2}$ in $^{\circ}$ ) parameters calculated for three conformations of $\mathbf{1 b}$ $5 \mathbf{b}$ $c c<c t<t$. Again, an exception occurs for MP2/def2TZVP, whose $\Delta E$ results for $\mathbf{5 b}$ suggest that the $t t$-conformation is slightly more favorable than the ct-conformation. In general, the differences in energies in all sequences of conformations span the range of several $\mathrm{kcal} / \mathrm{mol}$ and they divide the investigated compounds into two groups. Taking the values of $\Delta G$ obtained from B3LYP/def2-QZVPP into consideration, we can see that the $\Delta G$ values of the least favorable conformers do not exceed $3 \mathrm{kcal} / \mathrm{mol}$ for $\mathbf{1 a}-\mathbf{3 a}$ and $\mathbf{1 b}-\mathbf{3 b}$. In particular, the
$\Delta G$ values for the $t t$-conformers of $\mathbf{2 a}$ and $\mathbf{2 b}$ are lower than $2 \mathrm{kcal} / \mathrm{mol}$. On the other hand, the $\Delta G$ values calculated for the $t t-\mathbf{4 a}, t t-\mathbf{4 b}, t t-\mathbf{5} \mathbf{a}$ and $t t-\mathbf{5 b}$ are significantly larger, with the maximal value amounting to $8.94 \mathrm{kcal} / \mathrm{mol}$ for $t t-\mathbf{4 a}$.

The existence of both N,O-cis and N,O-trans conformations has been detected by FTIR for a series of 2-pyrrolyl chloromethyl ketones and 1-methyl-2-pyrrolyl chloromethyl ketones in cyclohexane solution [38]. In this case, the conformational stability is, however, governed 
mainly by intermolecular hydrogen bonding interactions. Theoretical calculations for isolated molecules of these ketones [38], as well as of several related compounds [3945], indicate that their N,O-cis conformers possess lower total electron energies than the respective N,O-trans conformers, which fully corresponds with the energetic ordering of the $c c$ - and $t t$-conformers for $4 \mathbf{a}$ and $\mathbf{5 a}$.

It is also expedient to compare our $\Delta E$ values for the conformers of $\mathbf{1 a}$ and $\mathbf{2 a}$ with the results of previous quantum chemical calculations [13, 15]. The comparison reveals that there is one significant discrepancy between our $\Delta E$ values and the previous ones. For the $c c$-conformer of 1a, Benassi et al. [13] have predicted that the $\Delta E$ value amounts to $7.55 \mathrm{kcal} / \mathrm{mol}$, whereas our values are 1.24 and $2.14 \mathrm{kcal} / \mathrm{mol}$, depending on the level of theory applied. The $\Delta E$ value of $7.55 \mathrm{kcal} / \mathrm{mol}$ seems to be severely overestimated, which most probably results from the poor accuracy and simplifications of the computational methodology used by Benassi et al.

Populations of individual conformers for each compound are also shown in Tables 1 and 2. These populations are based on the $\Delta G$ values inserted into the well-known Boltzmann formula. Expressing the $\Delta G$ values of individual conformations in terms of the populations of the corresponding conformers allows us to collate our results for 1a, 2a and $\mathbf{2 b}$ with the experimental data. Although the absolute values of the populations calculated in this work differ from those deduced from the experimental dipole moment measurements [11], two main findings are shared. First, the population of the $c t$-conformation is predominant for 1a, while the percentage of the $c c$-conformer outnumbers that of the $c t$-conformer for $\mathbf{2 a}$ and $\mathbf{2 b}$. In all these cases, the populations of the dominating conformer exceed $50 \%$. Second, the population of the $c c$-conformer grows on going from $\mathbf{2 a}$ to $\mathbf{2 b}$. Our results do not support the conjecture made by Lumbroso et al. [11] about the noticeable contribution of the $c c$-conformation in $\mathbf{1 a}$. According to the results of our calculations, the population of the $c c$-conformer is negligible (1\%). Instead of the $c c$ conformer, the $t$-conformer becomes abundant, with its population of 19 and $32 \%$ at the MP2/def2-TZVP and B3LYP/def2-QZVPP levels, respectively.

As stated previously, the $\Delta E$ values yielded by $\mathrm{MP} 2 /$ def2-TZVP and the corresponding B3LYP/def2-QZVPP values lead to the reverse ordering of two higher-energy conformations for $\mathbf{1 b}$ and $\mathbf{5 b}$. In order to establish whether the reverse ordering is a consequence of the quantum chemical method applied or the basis set effect, additional calculations using several quantum chemical methods in conjunction with the def2-QZVPP basis set have been performed. It is known that DFT methods do not account for dispersive interactions and, for that reason, B3LYP is combined with three versions of Grimme's dispersion correction. Selected representatives of WFT methods are also taken into account. Of them, the $\operatorname{CCSD}(\mathrm{T})$ method is used to provide reference results. Two reasons argue for selecting CCSD(T)/def2-QZVPP to be an appropriate level of theory for calculating reference energies reliably. The first reason is that the def2-QZVPP basis set is close to the complete basis set limit [46]. The second one relies on a highly likely assumption that post-CCSD(T) effects are insignificant [47]. Because of the very high computational cost of CCSD(T), only two compounds, namely $\mathbf{1 b}$ and its ketone counterpart, are considered here and the $\mathrm{CCSD}(\mathrm{T})$ method is used to calculate single-point energies for the conformers in their B3LYP/def2-QZVPP-optimized geometries. Table 3 presents the $\Delta E$ values obtained by the aforementioned DFT and WFT methods for $\mathbf{1 a}$ and $\mathbf{1 b}$ in three conformations. Perusing the tabulated results leads to several findings. First, the B3LYP/def2-QZVPP level of theory is able to reproduce the reference ordering of three conformations in $\mathbf{1 a}$ and $\mathbf{1 b}$. On this basis, it can be assumed that the sequences of conformations for $\mathbf{2} \mathbf{a}-\mathbf{5 a}$ and $\mathbf{2 b}-\mathbf{5 b}$ are also predicted by this method reliably. However, the comparison of the absolute $\Delta E$ values calculated by B3LYP/def2-QZVPP with the CCSD(T)/def2-QZVPP ones reveals that $\mathrm{B} 3 \mathrm{LYP} / \mathrm{def} 2-\mathrm{QZVPP}$ underestimates the $\Delta E$ values for the $t t$-conformers of $\mathbf{1 a}$ and $\mathbf{1 b}$, while the $\Delta E$ values of the $c c$-conformers are overestimated by ca. $0.5 \mathrm{kcal} / \mathrm{mol}$. In other words, B3LYP/def2-QZVPP overestimates the energy gap between the conformer of the lowest energy and the conformer of the highest energy. It is in line with previous reports for such energy gaps in $n$ alkanes [47] and cyclohexane derivatives [48]. Second, the addition of Grimme's dispersion correction to B3LYP has a noticeable influence on $\Delta E$ values, but it does not change the ordering in the sequences of conformations for both compounds. It is rather difficult to answer a question whether the presence of Grimme's dispersion correction improves the accuracy of the calculated $\Delta E$ values. It seems to be heavily dependent on the version of such a correction. B3LYP-D3/def2-QZVPP is outperformed by B3LYP/def2-QZVPP, while the other two B3LYP-D methods yield the $\Delta E$ values that are closer to the reference ones than those of B3LYP/def2-QZVPP. In particular, the D2 correction provides a noticeable improvement in the calculated $\Delta E$ values. Interestingly, D2 is the simplest dispersion correction of those considered here. A cursory review of literature reveals an ambiguous effect of dispersion correction on relative energies of conformers. On the one hand, Grimme's dispersion corrections considerably improve relative energies for selected conformers of 4-ethyl-4-methyloctane [49] and melatonin [50], but, on the other hand, the presence of such a correction leads to qualitatively wrong conformer ordering in alkanes [47]. Third, for all three B3LYP-D methods, the differences 
Table 3 Relative energies between conformers $(\Delta E$ in $\mathrm{kcal} / \mathrm{mol}$ ) calculated at various levels of theory for $\mathbf{1 a}$ and $\mathbf{1 b}$

\begin{tabular}{|c|c|c|c|c|c|c|}
\hline \multirow[t]{2}{*}{ Method } & \multicolumn{6}{|l|}{$\Delta E$} \\
\hline & $c c-\mathbf{1 a}$ & $c t-\mathbf{1 a}$ & $t t-\mathbf{1 a}$ & $c c-\mathbf{1 b}$ & $c t-\mathbf{1 b}$ & $t t-\mathbf{1 b}$ \\
\hline B3LYP/def2-QZVPP ${ }^{\mathrm{a}}$ & 2.14 & 0.00 & 0.34 & 1.46 & 0.00 & 0.31 \\
\hline B3LYP-D2/def2-QZVPP & 1.84 & 0.00 & 0.62 & 1.09 & 0.00 & 0.46 \\
\hline B3LYP-D3/def2-QZVPP & 2.25 & 0.00 & 0.47 & 1.59 & 0.00 & 0.30 \\
\hline B3LYP-D3(BJ)/def2-QZVPP & 1.91 & 0.00 & 0.58 & 1.37 & 0.00 & 0.43 \\
\hline MP2/def2-QZVPP ${ }^{\mathrm{b}}$ & 1.29 & 0.00 & 0.64 & 0.40 & 0.00 & 0.62 \\
\hline SCS-MP2/def2-QZVPP ${ }^{\mathrm{b}}$ & 1.32 & 0.00 & 0.76 & 0.39 & 0.00 & 0.70 \\
\hline $\mathrm{CCSD} / \mathrm{def} 2-\mathrm{QZVPP}{ }^{\mathrm{b}}$ & 1.56 & 0.00 & 0.89 & 0.82 & 0.00 & 0.79 \\
\hline $\operatorname{CCSD}(\mathrm{T}) /$ def2-QZVPP $^{\mathrm{b}}$ & 1.60 & 0.00 & 0.79 & 0.97 & 0.00 & 0.70 \\
\hline B3LYP-D2/def2-QZVPP ${ }^{c}$ & 1.71 & 0.00 & 0.63 & 1.00 & 0.00 & 0.48 \\
\hline B3LYP-D3/def2-QZVPP & 2.25 & 0.00 & 0.48 & 1.59 & 0.00 & 0.31 \\
\hline B3LYP-D3(BJ)/def2-QZVPP & 1.90 & 0.00 & 0.59 & 1.36 & 0.00 & 0.43 \\
\hline $\mathrm{MP} 2 /$ def2-QZVPP ${ }^{\mathrm{c}}$ & 1.22 & 0.00 & 0.65 & 0.51 & 0.00 & 0.61 \\
\hline
\end{tabular}

between the $\Delta E$ values obtained for the B3LYP/def2QZVPP-optimized conformers and for the geometries optimized using the dispersion-corrected versions of B3LYP are small, which indicates that the geometries of the conformers are not strongly affected by intramolecular dispersion. Fourth, the WFT results in Table 3 facilitate the assessment of the MP2/de2-TZVP results. One could suspect that the basis set effect is responsible for the quality of the MP2/def2-TZVP calculations. It is known that WFT methods generally require extended basis sets, while the def2-TZVP basis set is relatively modest, which may be the reason of inaccuracies in $E$. However, MP2/def2-QZVPP still predicts the reverse ordering of $c c-\mathbf{1 b}$ and $t t-\mathbf{1 b}$; hence, it excludes the basis set effect. In consequence, the MP2 method itself exhibits a deficiency in the values of $E$ for the conformers of $\mathbf{1 b}$ and $\mathbf{5 b}$. Fifth, the spin-component scaled variant of MP2 demonstrates poor accuracy in the calculated $\Delta E$ value for the $c c-\mathbf{1 b}$, which results in the wrong ordering of the $c c$ - and $t t$-conformers. On the other hand, SCS-MP2 shows an improvement in $\Delta E$ for 1a over MP2, which in turn is in line with previous reports on the improved performance of SCS-MP2 in providing the structural and energetic description of conformations for molecules $[50,51]$ and molecular complexes [52-54].

\section{Interconversion barriers}

Energy barriers for the interconversion between individual conformations in a molecule give an indication on how easy a change in the conformations occurs, and on this basis, a conclusion on the flexibility of molecular structure can be drawn. Now we attempt to establish what changes in the total electron energy $E$ are associated with the rotation of the whole heteroaryl substituent about the single $\mathrm{C}-\mathrm{C}$ bond linking this substituent with the $\mathrm{C}$ atom of (thio)carbonyl group. However, we are interested in estimating roughly the order of magnitude of changes in $E$ for the molecular motion involving such a rotation rather than in calculating the accurate values of energy barriers for the interconversion between individual conformations. In order to determine the relation between the $E$ energy and the rotation of heteroaryl substituent, a fragment of potential energy surfaces (PESs) for $\mathbf{2 a}, \mathbf{2} \mathbf{b}, \mathbf{4 a}$ and $\mathbf{4 b}$ has been examined. To be precise, a one-dimensional variant of the PESs has been probed with respect to the $\mathrm{X}-\mathrm{C}-\mathrm{C}=\mathrm{Y}$ dihedral angle, ranging from $0^{\circ}$ to $360^{\circ}$ (in the case of $\mathbf{4 a}$ and $4 \mathbf{b}$, the $\mathrm{N}$ atom of their 2-pyrrolyl substituents corresponds to $\mathrm{X}$ in the $\mathrm{X}-\mathrm{C}-\mathrm{C}=\mathrm{Y}$ angle). This angle will be denoted here by $\tau_{1}$, and its changes define the rotation of one heteroaryl substituent about the single $\mathrm{C}-\mathrm{C}$ bond. The arrangement of the other heteroaryl substituent is kept fixed, and it corresponds to either the X,Y-cis orientation found in the fully optimized $c c$-conformer or the X,Y-trans orientation of the fully optimized $t t$-conformer. As a result, two sets of geometries with different $\tau_{1}$ angles have been generated for each of the four above-mentioned compounds, and then for each geometry, its single-point energy is calculated at the B3LYP/def2-QZVPP level of theory. Such a computational procedure allows us to express $E$ as a function of $\tau_{1}$, and the PESs obtained in this manner are shown in Fig. 1. To make the analysis of the PESs easy, the energy scales in Fig. 1 present relative energies. In the upper plot, the $E$ energies of $c c-\mathbf{2 a}, c c-\mathbf{2} \mathbf{b}, c c-\mathbf{4 a}$ and $c c-\mathbf{4 b}$ are assumed to be zero, whereas $c t-\mathbf{2} \mathbf{a}, c t-\mathbf{2} \mathbf{b}, c t-\mathbf{4} \mathbf{a}$ and $c t$ - 
Fig. 1 PESs for the rotation of heteroaryl substituent in $\mathbf{2 a}, \mathbf{2 b}$, $\mathbf{4 a}$ and $\mathbf{4 b}$. Relative energies are given in $\mathrm{kcal} / \mathrm{mol}$, and the angle of rotation $\left(\tau_{1}\right.$ in $\left.{ }^{\circ}\right)$ is assumed to change in the range from $0^{\circ}$ to $360^{\circ}$
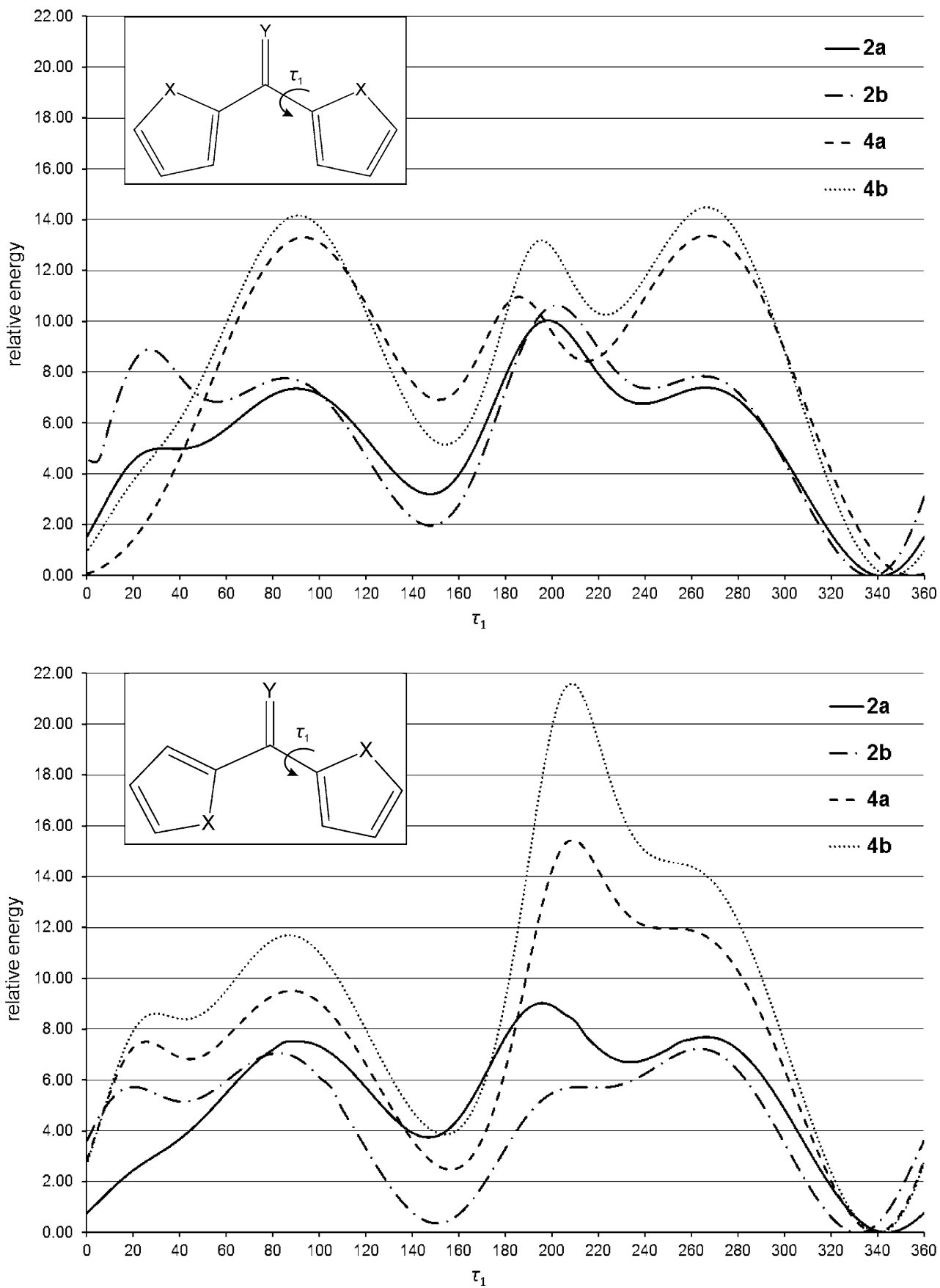

4b occupy the zero level in energy in the bottom plot. It should be stressed that in general the relative energy shown in Fig. 1 is not identical to the $\Delta E$ energy discussed in the previous section because the latter is determined for fully optimized geometries.

A quick glance at the plots in Fig. 1 reveals that several local minima and maxima appear on the PESs. The relatively complex shape of the PESs suggests that the rotation of one heteroaryl substituent is affected by the presence of the other heteroaryl substituent, and it is dependent on the orientation of the other substituent. The local minima occurring for $\tau_{1}$ around $150^{\circ}$ in the upper and bottom plots correspond to the $c t$ - and the $t t$-conformations, respectively (although these minima are not the conformers whose structures are fully optimized). The upper plot shows that the interconversion from the $c c$-conformation to the $c t$ conformation requires surmounting the barriers of at least several $\mathrm{kcal} / \mathrm{mol}$, while the bottom plot indicates that the barriers of the interconversion from the $t t$-conformation to the $c t$-conformation are even higher. The values of relative 
energy at the highest energy points on the PESs are 10.02, $10.61,15.43$ and $21.56 \mathrm{kcal} / \mathrm{mol}$ for $\mathbf{2 a}, \mathbf{2 b}, \mathbf{4 a}$ and $\mathbf{4 b}$, respectively. These maximal values of relative energy allow us to estimate the magnitude of energy barriers for the rotation of the 2-thiophenyl and 2-pyrrolyl groups. The maximal values of relative energy for $\mathbf{2 a}$ and $\mathbf{2} \mathbf{b}$ occur for the transition of the 2-thiophenyl group from the $\mathrm{S}, \mathrm{Y}$-cis to S,Y-trans orientation, with the second 2-thiophenyl group being in the S,Y-cis orientation. The other orientation of the second 2-thiophenyl group lowers slightly the maximal values of relative energy on going from the $c t$-conformer to the $t t$-conformer. The rotation of the 2-pyrrolyl group is accompanied by larger values of relative energy than those observed for the rotation of the 2-thiophenyl group. The maximal values of relative energy in $\mathbf{4 a}$ and $\mathbf{4 b}$ are found for the transition from the $c t$-conformation to the $t t$-conformation, which indicates that the latter is not easily adopted. It correlates with the negligible population of the $t t$-conformer for these compounds. The maximal relative energy predicted here for the rotation from $c c-\mathbf{2 a}$ to $c t-\mathbf{2 a}$ $(9.02 \mathrm{kcal} / \mathrm{mol})$ is not very far from the experimental activation energy of $7.48 \mathrm{kcal} / \mathrm{mol}$ found for the transition between the $c t$-conformation and the $t t$-conformation in the ketyl radical generated from di-2-thiophenyl ketone [55]. The presence of a heteroaryl group may hinder the rotation of another heteroaryl group in diheteroaryl ketone or thioketone. The comparison of the difference in relative energy at the highest and lowest energy points on the PESs for 4a with the energy barrier calculated previously for 2-pyrrolyl aldehyde [56, 57] shows that the former is approximately twice as large as the latter. Similarly, the energy barrier for 2a demonstrates a higher value when it is collated with the values of energy barriers calculated for 2-thiophenyl aldehyde [58] and thiophene-2-carbonyl fluoride [59].

In principle, the magnitude of maximal relative energies for $\mathbf{2 a}$ and $\mathbf{2 b}$ is different from that for $\mathbf{4 a}$ and $\mathbf{4 b}$. Irrespective of whether one 2-thiophenyl group is in its S, Y-cis or S,Y-trans orientation, the rotation of the other 2-thiophenyl group leads to smaller energy barriers than those occurring for the rotation of the 2-pyrrolyl group in $\mathbf{4 a}$ and 4b. It is in line with the division of the investigated compounds into two groups with respect to the magnitude of $\Delta E$, as it was mentioned in the previous section. The heights of the energy barriers in Fig. 1 correlate qualitatively with the previously presented values of $\Delta E$. The values of $\Delta E$ for the conformers of $\mathbf{2 a}$ and $\mathbf{2} \mathbf{b}$ are smaller than the $\Delta E$ values for $\mathbf{4 a}$ and $\mathbf{4 b}$. Similarly, the maximal relative energies for $\mathbf{2 a}$ and $\mathbf{2 b}$ do not exceed $10.6 \mathrm{kcal} /$ mol, whereas the maximal values of relative energy for $\mathbf{4 a}$ and $\mathbf{4 b}$ are much greater. It generally leads to the conclusion that $\mathbf{2 a}$ and $\mathbf{2 b}$ are more flexible systems than $\mathbf{4 a}$ and 4b. The higher-energy barrier for the rotation of 2-pyrrolyl group compared to the rotational barrier of 2-thiophenyl group is also observed for 2-heteroaryl chromium aminocarbene [60].

The magnitude of energy barriers in $\mathbf{2 a}, \mathbf{2 b}, \mathbf{4 a}$ and $\mathbf{4 b}$ is also affected by the kind of the $\mathrm{Y}$ atom. For the transition from the $c c$-conformation to the $c t$-conformation, thioketones exhibit higher relative energies of local maxima and lower relative energies of local minima around $\tau_{1}$ of $150^{\circ}$ on the PESs than the corresponding ketones.

To conclude the discussion on the interconversion barriers, we can expect that the rotation of heteroaryl substituents in $\mathbf{4 a}, \mathbf{4 b}, \mathbf{5 a}$ and $\mathbf{5 b}$ is more restricted than the rotation of heteroaryl substituents in the remaining compounds. Furthermore, the rotation of heteroaryl fragments in thioketones turns out to be more hindered than in the corresponding ketones.

\section{Geometries}

Let us now describe briefly the optimized geometries of the conformers found for $\mathbf{1} \mathbf{a}-\mathbf{5 a}$ and $\mathbf{1 b}-\mathbf{5 b}$. For all these compounds, their $c c$ - and $t t$-conformers exhibit the $\mathrm{C}_{2}$ point group symmetry, with the twofold rotation axis lying along the double bond of (thio)carbonyl group. As for the $c t$ conformers of the compounds, their optimized geometries do not manifest the presence of any rotation axis or mirror plane. We will focus on one characteristic feature of the geometries of the investigated compounds, namely on the spatial orientation of the heteroaryl groups with respect to the (thio)carbonyl group. Two dihedral $\mathrm{X}-\mathrm{C}-\mathrm{C}=\mathrm{Y}$ angles define such an orientation and their changes dictate to the rotation of the heteroaryl rings about the single $\mathrm{C}-\mathrm{C}$ bonds (as it was described in the previous section). These two angles will be referred to as $\tau_{1}$ and $\tau_{2}$, and their values occurring in the conformers of $\mathbf{1 a}-\mathbf{5 a}$ and $\mathbf{1 b}-\mathbf{5 b}$ are listed in Tables 1 and 2. For the $c c$ - and $t t$-conformers, whose geometries belong to the $\mathrm{C}_{2}$ point group, the values of $\tau_{1}$ and $\tau_{2}$ are obviously identical. In general, two heteroaryl substituents being a part of each conformer in the investigated compounds prefer a non-planar orientation and their planes are leaned outward in the opposite directions. The values of $\tau_{1}$ and $\tau_{2}$ additionally give us an indication on the deviation of the heteroaryl rings from a coplanar arrangement with the (thio)carbonyl group. There are, however, two exceptions to the non-planar arrangement of the heteroaryl rings. $t t-\mathbf{1 a}$ demonstrates a strictly planar molecular geometry. The orientation of two 2-furanyl groups in $c t$-1a is also very close to coplanarity both with each other and with the carbonyl group.

It is interesting to analyze some possible relations between $\tau_{1}$ or $\tau_{2}$ and the kind of $\mathrm{X}$ and $\mathrm{Y}$ in the investigated compounds. For the $c c$-conformation, the distortion of the heteroaryl groups from a coplanar arrangement with 
the (thio)carbonyl group diminishes gradually along the sequence of $\mathrm{X}: \mathrm{N}-\mathrm{Me}>\mathrm{S}>\mathrm{Se}>\mathrm{O}>\mathrm{N}-\mathrm{H}$. In the case of the $t$-conformation, the decrease in the distortion from planarity follows the sequence in $\mathrm{X}: \mathrm{N}-\mathrm{Me}>\mathrm{Se}>$ $\mathrm{S}>\mathrm{N}-\mathrm{H}>\mathrm{O}$. It is rather obvious that the bulkiest $\mathrm{X}$ of those considered here, that is $\mathrm{N}-\mathrm{Me}$, prevents both $c c$ - and $t t$-conformers from adopting a planar structure. When $\mathrm{X}$ is a group 16 heteroatom and it changes from $\mathrm{O}$ to $\mathrm{Se}$, the distortion in the $t t$-conformation correlates with the growing size of the heteroatoms. For this conformation, the heteroatoms are close to each other, and thus, their lone electron pairs are in the immediate neighborhood, which seems to directly affect the distortion of the heteroaryl substituents. The magnitude of the distortion of conformer geometry from planarity is also dependent on the kind of the $\mathrm{Y}$ atom. Ketones 1a-5a possess the heteroaryl substituents whose planes are leaned less outward than it is in the corresponding thioketones $\mathbf{1 b}-\mathbf{5} \mathbf{b}$.

We end the analysis of the calculated $\tau_{1}$ and $\tau_{2}$ structural parameters by comparing them with the available experimental data. According to an early experimental dipole moment measurement for the preferred conformer of $\mathbf{2 a}$ in solution, a dihedral angle of $45^{\circ} \pm 10^{\circ}$ between the planes of two 2-thiophenyl rings has been inferred [10]. A more recent experimental study of the crystal structure of $\mathbf{2 a}$ reports that the $\mathrm{S}-\mathrm{C}-\mathrm{C}=\mathrm{O}$ angle in the $c c$-conformer amounts to $-21.6^{\circ}$ [13]. Our values of $\tau_{1}$ and $\tau_{2}$ calculated for $c c-\mathbf{2} \mathbf{a}$ in the gas phase predict a slightly less distorted geometry.

\section{NBO analysis}

In order to better understand the reasons for the conformational behavior of $\mathbf{1 a}-\mathbf{5 a}$ and $\mathbf{1 b}-\mathbf{5 b}$, the NBO analysis of their conformers has been carried out. Within the framework of the NBO analysis, the total energy of a molecule can be decomposed into a Lewis-type component $E^{\mathrm{L}}$ and a non-Lewis-type component $E^{\mathrm{NL}}$. The former represents the energy of an idealized structure with all bonds and lone pair orbitals perfectly localized and doubly occupied. The latter describes the energetic effect arising from the deviation of the molecule from its idealized structure, and thus, it can be used as a measure of electron delocalization [33].

Here, the B3LYP/def2-QZVPP total energy of each conformer for $\mathbf{1 a}-\mathbf{5 a}$ and $\mathbf{1 b}-\mathbf{5 b}$ is decomposed into the $E^{\mathrm{L}}$ and $E^{\mathrm{NL}}$ components, and their values are expressed relative to $E^{\mathrm{L}}$ and $E^{\mathrm{NL}}$ found for the preferred conformer of each compound. The resulting $\Delta E^{\mathrm{L}}$ and $\Delta E^{\mathrm{NL}}$ values are presented in Tables 4 and 5. They allow us to estimate the relative importance of $E^{\mathrm{L}}$ and $E^{\mathrm{NL}}$ in establishing the energetic ordering of individual conformers for each compound. According to the values of $\Delta E^{\mathrm{L}}$, the $c c$-conformation turns out to be least stable for all investigated compounds except 1b. However, this conformation is favored by $E^{\mathrm{NL}}$ and the values of $\Delta E^{\mathrm{NL}}$ evolve in the sequence $c c<c t<t t$ for the majority of the compounds. The greatest stabilization of the $c c$-conformation by the $E^{\mathrm{NL}}$ component can be clarified in terms of electron delocalization. Strictly speaking, a significant $\pi$-conjugation is expected for a trans arrangement of the $\mathrm{C}=\mathrm{Y}$ bond and the adjacent $\mathrm{C}=\mathrm{C}$ bond of the heterocyclic ring (for this bond, there is a high $\pi$-electron density) [10, 61]. This $\pi$-conjugation can be illustrated by the energies of specific donoracceptor interactions $E^{(2)}$ estimated using a standard second-order perturbation treatment [33]. As a matter of fact, the values of $E^{(2)}$ for the delocalizing interactions between the $\pi$ - and $\pi^{*}$-orbitals of the $\mathrm{C}=\mathrm{Y}$ group and of the heteroaryl rings most often become less and less negative in the sequence from $c c$ to $c t$ and to $t$, which means that the $c c$-conformation is stabilized by these interactions most effectively. In addition, the trend in the inner stabilization of the heteroaryl substituents (that is, the delocalization between the lone pairs of the heteroatoms and the $\pi^{*}$-orbitals of the rings) imitates this sequence strictly. The $\mathrm{LP}_{\mathrm{Xs}} \rightarrow \pi_{\text {rings }}^{*}$ interaction and generally the interactions taking place between the orbitals of each heteroaryl substituents are large in magnitude, which is obviously a consequence of the strong delocalization over every aromatic ring. In the case of $\mathbf{1 a}$ and $\mathbf{1 b}$, the values of $E^{(2)}$ also give a clear indication on the reasons for the low stabilization of their $c c$-conformers. For these two compounds, the stabilization resulting from the $\pi_{\text {rings }} \rightarrow \pi_{\mathrm{C}=\mathrm{Y}}^{*}$ delocalization shows less negative $E^{(2)}$ values for the $c c$-conformers than for the other conformers. The difference in the $E^{(2)}$ values of the $\mathrm{LP}_{\mathrm{Xs}} \rightarrow \pi_{\text {rings }}^{*}$ delocalization for the $c c$ - and $t t$-conformers of $\mathbf{1 a}$ and $\mathbf{1 b}$ is also smaller than for the remaining compounds. The trend in the $E^{(2)}$ values of the $\pi$-conjugative interactions that favor the $c c$-conformation in $\mathbf{2} \mathbf{a}-\mathbf{5 a}$ and $\mathbf{2} \mathbf{b}-\mathbf{5 b}$ is usually opposite to that observed for the $E^{(2)}$ values of $\sigma$-hyperconjugative interactions. In general, the hyperconjugative interaction between $\sigma_{\mathrm{C}=\mathrm{Y}}$ and $\sigma_{\text {rings }}^{*}$ stabilizes the $t$-conformation most effectively.

The values of the delocalizing interactions between the orbitals of the heteroaryl substituents and the orbitals of the $\mathrm{C}=\mathrm{Y}$ groups are less negative for the ketones than for the corresponding thioketones, and therefore, the stabilization resulting from these interactions is diminished for $\mathbf{1 a - 5 a}$ relative to the corresponding $\mathbf{1 b}-\mathbf{5} \mathbf{b}$. The $\sigma, \sigma^{*}, \pi$ and $\pi^{*}$ orbitals of carbonyl group lie much higher in energy than those of thiocarbonyl group, while the energies of the orbitals of the heteroaryl substituents change only slightly while going from the ketones to the corresponding 
Table 4 Relative energies $(\Delta E)$ and some selected results of the NBO analysis for 1a-5a in three conformations

\begin{tabular}{|c|c|c|c|c|c|c|c|c|c|}
\hline \multirow[t]{2}{*}{ Conformer } & \multirow[t]{2}{*}{$\Delta E^{\mathrm{a}}$} & \multirow[t]{2}{*}{$\Delta E^{\mathrm{L}}$} & \multirow[t]{2}{*}{$\Delta E^{\mathrm{NL}}$} & \multirow[t]{2}{*}{$\Delta E^{\mathrm{SX}}$} & \multicolumn{5}{|l|}{$E^{(2)}$} \\
\hline & & & & & $\sigma_{\mathrm{C}=\mathrm{Y}} \rightarrow \sigma_{\text {rings }}^{*}$ & $\pi_{\mathrm{C}=\mathrm{Y}} \rightarrow \pi_{\text {rings }}^{*}$ & $\sigma_{\text {rings }} \rightarrow \sigma_{\mathrm{C}=\mathrm{Y}}^{*}$ & $\pi_{\text {rings }} \rightarrow \pi_{\mathrm{C}=\mathrm{Y}}^{*}$ & $\mathrm{LP}_{\mathrm{Xs}} \rightarrow \pi_{\text {rings }}^{*}$ \\
\hline$c c-\mathbf{1 a}$ & 1.24 & 2.49 & -0.35 & -4.79 & -2.80 & -11.60 & -2.88 & -35.70 & -118.04 \\
\hline$c t-\mathbf{1 a}$ & 0.00 & 0.00 & 0.00 & 0.00 & -3.63 & -11.64 & -2.56 & -40.80 & -113.91 \\
\hline$t t-\mathbf{1 a}$ & 0.51 & -0.75 & 1.10 & -2.62 & -4.28 & -10.44 & -2.26 & -41.78 & -114.18 \\
\hline$c c-\mathbf{2 a}$ & 0.00 & 0.00 & 0.00 & 0.00 & -3.48 & -10.82 & -3.04 & -37.44 & -97.90 \\
\hline$c t-\mathbf{2 a}$ & 0.77 & -8.82 & 9.59 & -5.39 & -3.56 & -9.75 & -3.43 & -37.90 & -94.77 \\
\hline$t t-\mathbf{2 a}$ & 1.85 & -5.50 & 7.35 & -4.18 & -3.62 & -8.40 & -4.06 & -37.88 & -92.16 \\
\hline$c c-\mathbf{3 a}$ & 0.00 & 0.00 & 0.00 & 0.00 & -3.62 & -11.10 & -3.04 & -37.80 & -74.08 \\
\hline$c t-\mathbf{3 a}$ & 1.41 & -7.74 & 9.15 & -6.78 & -3.75 & -9.77 & -3.83 & -37.05 & -71.70 \\
\hline$t t-\mathbf{3 a}$ & 2.93 & -5.96 & 8.89 & -6.99 & -3.90 & -8.32 & -4.90 & -36.50 & -69.02 \\
\hline$c c-\mathbf{4 a}$ & 0.00 & 0.00 & 0.00 & 0.00 & -3.98 & -12.08 & -3.02 & -48.18 & -158.38 \\
\hline$c t-\mathbf{4 a}$ & 3.82 & -14.73 & 18.54 & -22.18 & -3.83 & -10.97 & -2.86 & -42.57 & -153.88 \\
\hline$t t-\mathbf{4 a}$ & 8.99 & -25.26 & 34.25 & -27.56 & -3.76 & -9.50 & -2.64 & -38.04 & -132.62 \\
\hline$c c-\mathbf{5 a}$ & 0.00 & 0.00 & 0.00 & 0.00 & -3.24 & -10.32 & -3.84 & -44.06 & -156.42 \\
\hline$c t-\mathbf{5 a}$ & 5.37 & -9.12 & 14.49 & -3.16 & -3.40 & -8.94 & -2.95 & -36.55 & -146.11 \\
\hline$t t-\mathbf{5 a}$ & 9.63 & -19.82 & 29.45 & -4.34 & -3.72 & -7.62 & -2.10 & -31.14 & -141.20 \\
\hline
\end{tabular}

The NBO quantities are described in the text. All values in $\mathrm{kcal} / \mathrm{mol}$

${ }^{a}$ Repeated after Table 1

Table 5 Relative energies $(\Delta E)$ and some selected results of the NBO analysis for $\mathbf{1 b}-\mathbf{5 b}$ in three conformations

\begin{tabular}{|c|c|c|c|c|c|c|c|c|c|}
\hline \multirow[t]{2}{*}{ Conformer } & \multirow[t]{2}{*}{$\Delta E^{\mathrm{a}}$} & \multirow[t]{2}{*}{$\Delta E^{\mathrm{L}}$} & \multirow[t]{2}{*}{$\Delta E^{\mathrm{NL}}$} & \multirow[t]{2}{*}{$\Delta E^{\mathrm{SX}}$} & \multicolumn{5}{|l|}{$E^{(2)}$} \\
\hline & & & & & $\sigma_{\mathrm{C}=\mathrm{Y}} \rightarrow \sigma_{\text {rings }}^{*}$ & $\pi_{\mathrm{C}=\mathrm{Y}} \rightarrow \pi_{\text {rings }}^{*}$ & $\sigma_{\text {rings }} \rightarrow \sigma_{\mathrm{C}=\mathrm{Y}}^{*}$ & $\pi_{\text {rings }} \rightarrow \pi_{\mathrm{C}=\mathrm{Y}}^{*}$ & $\mathrm{LP}_{\mathrm{Xs}} \rightarrow \pi_{\text {rings }}^{*}$ \\
\hline$c c-\mathbf{1 b}$ & 1.47 & -2.72 & 4.18 & -4.08 & -6.96 & -20.44 & -3.82 & -41.20 & -118.58 \\
\hline$c t-\mathbf{1 b}$ & 0.00 & 0.00 & 0.00 & 0.00 & -8.79 & -20.47 & -3.38 & -48.63 & -114.08 \\
\hline$t t-\mathbf{1 b}$ & 0.31 & -0.73 & 1.04 & -7.88 & -9.14 & -17.62 & -3.10 & -48.34 & -114.32 \\
\hline$c c-\mathbf{2 b}$ & 0.00 & 0.00 & 0.00 & 0.00 & -7.48 & -17.72 & -4.14 & -43.72 & -97.84 \\
\hline$c t-\mathbf{2} \mathbf{b}$ & 0.99 & -5.91 & 6.90 & -3.74 & -7.46 & -16.13 & -4.70 & -42.49 & -94.50 \\
\hline$t t-\mathbf{2 b}$ & 2.21 & -6.08 & 8.30 & -13.19 & -7.36 & -14.58 & -5.62 & -41.62 & -91.54 \\
\hline$c c-\mathbf{3 b}$ & 0.00 & 0.00 & 0.00 & 0.00 & -7.56 & -18.02 & -4.34 & -44.76 & -73.88 \\
\hline$c t-\mathbf{3 b}$ & 1.43 & -5.82 & 7.25 & -4.97 & -7.58 & -16.26 & -5.21 & -41.90 & -71.30 \\
\hline$t t-\mathbf{3 b}$ & 2.99 & -6.72 & 9.71 & -15.79 & -7.84 & -14.72 & -6.66 & -40.80 & -68.48 \\
\hline$c c-\mathbf{4 b}$ & 0.00 & 0.00 & 0.00 & 0.00 & -8.72 & -18.42 & -4.14 & -59.60 & -161.60 \\
\hline$c t-\mathbf{4 b}$ & 3.92 & -8.66 & 12.58 & -5.54 & -8.87 & -17.77 & -3.69 & -51.78 & -152.82 \\
\hline$t t-\mathbf{4 b}$ & 9.41 & -24.86 & 34.26 & -20.30 & -8.48 & -16.36 & -3.42 & -45.58 & -134.20 \\
\hline$c c-\mathbf{5 b}$ & 0.00 & 0.00 & 0.00 & 0.00 & -6.74 & -15.06 & -4.92 & -50.52 & -155.48 \\
\hline$c t-\mathbf{5} \mathbf{b}$ & 3.06 & -5.77 & 8.83 & -7.06 & -7.36 & -14.46 & -3.93 & -43.54 & -150.62 \\
\hline$t t-5 \mathbf{b}$ & 5.04 & -13.30 & 18.35 & -9.90 & -8.22 & -13.80 & -2.96 & -38.58 & -143.22 \\
\hline
\end{tabular}

The NBO quantities are described in the text. All values in $\mathrm{kcal} / \mathrm{mol}$

${ }^{\text {a }}$ Repeated after Table 2

thioketones. It leads to larger energy gaps between the donor and acceptor orbitals for the ketones. Since each value of $E^{(2)}$ depends inversely on the energy gap between the respective donor and acceptor orbitals, the larger energy gaps encountered in the ketones result in less negative $E^{(2)}$ values and hence the smaller stabilization of the 
ketones. It emphasizes that the delocalization due to the conjugative and hyperconjugative interactions with the carbonyl group is less efficient than that involving the interactions with the thiocarbonyl group. It is in line with the findings reported in previous comparative NBO studies of various carbonyl and thiocarbonyl compounds [62-64]. The larger stabilization through the $\pi$-conjugative orbital interactions occurs in $\mathbf{1 b}-\mathbf{5 b}$ in spite of the spatial arrangement of their heteroaryl substituents. The heteroaryl substituents in $\mathbf{1 b}-\mathbf{5 b}$ are more leaned outward than in the corresponding $\mathbf{1 a}-\mathbf{5 a}$, and it actually should reduce the $\pi$-conjugation between the heteraryl substituents and the $\mathrm{C}=\mathrm{S}$ group.

The importance of electron delocalization in governing the conformational behavior of the investigated compounds can also be deduced from the values of $\Delta E^{\mathrm{SX}}$. Within the framework of the NBO steric analysis [65], donor-donor orbital interactions are taken into consideration in order to estimate the magnitude of steric exchange energy $E^{\mathrm{SX}}$ in a molecule. Tables 4 and 5 present the $\Delta E^{\mathrm{SX}}$ energies that are calculated relative to the $E^{\mathrm{SX}}$ energy of the preferred conformer for each compound. It should be noted here that the use of DFT wave functions may sometimes lead to unphysical artifacts in NBO steric calculations [66], and therefore, the correctness of the findings presented in this paragraph has been also confirmed at the HF/def2-QZVPP level (see Tables S3 and S4, Electronic Supplementary Material). It is evident from the tabulated values of $\Delta E^{\mathrm{SX}}$ that the conformers other than the preferred ones exhibit negative values of $\Delta E^{\mathrm{SX}}$ (the $E^{\mathrm{SX}}$ values themselves are positive, so the negative values of $\Delta E^{\mathrm{SX}}$ for these other conformers correspond to $E^{\mathrm{SX}}$ that are less positive than the $E^{\mathrm{SX}}$ values of the preferred conformers). It means that for each compound its preferred conformer is characterized by the largest steric repulsion. However, the stabilization energy of donor-acceptor delocalization more than compensate for such an unfavorable effect. It implies that the delocalizing orbital interactions acting in $\mathbf{1 a - 5 a}$ and $\mathbf{1 b}-\mathbf{5} \mathbf{b}$ are a very important factor influencing the stability and ordering of their conformers.

\section{IQA analysis}

Having analyzed the natural orbital viewpoint on the conformational stability of the investigated ketones and thioketones, let us now examine the fundamental intramolecular energetic effects governing the conformational behavior of these compounds from a different (that is, orbital free) perspective.

The results of the IQA analysis performed for charge density distributions calculated at the B3LYP/def2-QZVPP level of theory are given in Tables 6 and 7 . The $\Delta E$ values calculated using the IQA method differ slightly from the corresponding values obtained from ordinary single-point B3LYP/def2-QZVPP calculations (see Tables 1 and 2). The deviations in the IQA values of $\Delta E$ amount to $0.37 \mathrm{kcal} / \mathrm{mol}$ at the very most, and these deviations result from numerical inaccuracies in integrations over atomic basins. Because IQA calculations generally are very timeconsuming, the basin quadratures and integration methods used in our IQA calculations have been of standard quality in order to lower slightly the computational cost of these calculations. In Tables 6 and 7, several IQA energy components are presented relative to the values of these components found for the preferred conformer of each compound. All the IQA energy components shown in the tables are described in detail in Section S1; see Electronic Supplementary Material.

In general, two monotonous regularities in the values of IQA energy components are clearly evident for $\mathbf{1 a - 3 a}$ and 1b-3b. The values of $\Delta E^{\text {intra }}$ become more and more negative while going from the $c c$-conformers of these compounds to their $c t$-conformers and further to their $t t$ conformers, which means that the stabilizing influence of the intraatomic energy $E^{\text {intra }}$ is largest for the $t t$-conformers. The opposite trend occurs for the values of $\Delta E^{\text {inter }}$, and the interatomic interaction energy $E^{\text {inter }}$ is most energetically favorable for the $c c$-conformers of $\mathbf{1 a}-\mathbf{3 a}$ and $\mathbf{1 b}-\mathbf{3 b}$. From the trends in $E^{\text {intra }}$ and $E^{\text {inter }}$, it can be concluded that the $E^{\text {inter }}$ component is responsible for the preference of the $c c$ conformation in $\mathbf{2 a}, \mathbf{2 b}, \mathbf{3 a}$ and $\mathbf{3 b}$.

Within the framework of the IQA theory, various intramolecular energetic effects can be classified with respect to their physical nature. Accordingly, the values of $\Delta E$ are partitioned into the kinetic energy component $\Delta E_{\mathrm{kin}}$, the classical electrostatic component $\Delta E_{\mathrm{elst}}$ and the purely quantum mechanical, exchange-correlation component $\Delta E_{\mathrm{xc}}$. For all investigated compounds, the $\Delta E_{\text {kin }}$ component definitely disfavors their preferred conformers. In consequence, the conformational preference for the majority of the compounds is established on grounds of electrostatic and exchange-correlation interactions. For a few higher-energy conformers, their $\Delta E_{\text {elst }}$ values are negative, but in such cases the large and positive $\Delta E_{\mathrm{xc}}$ component outweighs and shifts these conformers higher in $\Delta E$. Although the $E_{\mathrm{xc}}$ energy is regarded as a quantum mechanical correction whose order of magnitude is one or two times smaller than that of $E_{\text {elst }}$, the importance of $\Delta E_{\mathrm{xc}}$ in ordering the higher-energy conformers is usually comparable to that of $\Delta E_{\text {elst. }}$ The trend in the values of $\Delta E_{\mathrm{xc}}$ always remains in qualitative agreement with that observed for $\Delta E$.

Tables 6 and 7 also show the interatomic components of electrostatic energy $E_{\text {elst }}^{\text {inter }}$ and exchange-correlation energy $E_{\mathrm{xc}}^{\mathrm{inter}}$. The magnitude of $E_{\mathrm{elst}}^{\mathrm{inter}}$ is much smaller than its 
Table 6 Some selected results of the IQA analysis for 1a-5a in three conformations

\begin{tabular}{|c|c|c|c|c|c|c|c|c|}
\hline Conformer & $\Delta E$ & $\Delta E^{\text {intra }}$ & $\Delta E^{\mathrm{inter}}$ & $\Delta E_{\text {kin }}$ & $\Delta E_{\mathrm{elst}}$ & $\Delta E_{\mathrm{xc}}$ & $E_{\text {elst }}^{\text {inter }}$ & $E_{\mathrm{xc}}^{\text {inter }}$ \\
\hline$c c-\mathbf{1 a}$ & 1.99 & 11.58 & -9.58 & -2.07 & 1.87 & 2.19 & -938.23 & -4279.71 \\
\hline$c t-\mathbf{1 a}$ & 0.00 & 0.00 & 0.00 & 0.00 & 0.00 & 0.00 & -931.39 & -4276.97 \\
\hline$t t-\mathbf{1 a}$ & 0.12 & -4.90 & 5.02 & -1.17 & 0.80 & 0.49 & -926.38 & -4276.96 \\
\hline$c c-\mathbf{2 a}$ & 0.00 & 0.00 & 0.00 & 0.00 & 0.00 & 0.00 & -77.79 & -4393.68 \\
\hline$c t-\mathbf{2 a}$ & 0.99 & -5.32 & 6.31 & 0.05 & 0.38 & 0.55 & -73.80 & -4391.36 \\
\hline$t t-\mathbf{2 a}$ & 1.86 & -9.77 & 11.63 & -1.90 & 2.11 & 1.66 & -69.81 & -4390.03 \\
\hline$c c-\mathbf{3 a}$ & 0.00 & 0.00 & 0.00 & 0.00 & 0.00 & 0.00 & -201.02 & -4298.63 \\
\hline$c t-\mathbf{3 a}$ & 1.31 & -7.59 & 8.90 & 0.29 & -0.48 & 1.51 & -194.38 & -4296.37 \\
\hline$t t-\mathbf{3 a}$ & 2.87 & -14.94 & 17.82 & -1.70 & 0.74 & 3.84 & -187.30 & -4294.53 \\
\hline$c c-\mathbf{4 a}$ & 0.00 & 0.00 & 0.00 & 0.00 & 0.00 & 0.00 & -885.25 & -4691.47 \\
\hline$c t-\mathbf{4 a}$ & 4.05 & -0.11 & 4.17 & -2.81 & 3.66 & 3.20 & -881.08 & -4691.47 \\
\hline$t t-\mathbf{4 a}$ & 9.33 & -16.68 & 26.01 & -8.53 & 10.36 & 7.50 & -859.98 & -4690.73 \\
\hline$c c-\mathbf{5 a}$ & 0.00 & 0.00 & 0.00 & 0.00 & 0.00 & 0.00 & -769.17 & -5867.63 \\
\hline$c t-\mathbf{5 a}$ & 5.00 & -10.28 & 15.29 & -4.23 & 5.12 & 4.12 & -754.74 & -5866.77 \\
\hline$t t-\mathbf{5 a}$ & 9.59 & -5.82 & 15.41 & -8.32 & 10.44 & 7.47 & -754.57 & -5866.82 \\
\hline
\end{tabular}

The IQA quantities are explained in the text. All values in $\mathrm{kcal} / \mathrm{mol}$
Table 7 Some selected results of the IQA analysis for $\mathbf{1 b}-\mathbf{5 b}$ in three conformations

\begin{tabular}{|c|c|c|c|c|c|c|c|c|}
\hline Conformer & $\Delta E$ & $\Delta E^{\text {intra }}$ & $\Delta E^{\text {inter }}$ & $\Delta E_{\text {kin }}$ & $\Delta E_{\text {elst }}$ & $\Delta E_{\mathrm{xc}}$ & $E_{\text {elst }}^{\text {inter }}$ & $E_{\mathrm{xc}}^{\text {inter }}$ \\
\hline$c c-\mathbf{1 b}$ & 1.45 & 21.85 & -20.40 & -1.63 & 2.00 & 1.08 & -563.36 & -4309.08 \\
\hline$c t-\mathbf{1} \mathbf{b}$ & 0.00 & 0.00 & 0.00 & 0.00 & 0.00 & 0.00 & -546.97 & -4305.08 \\
\hline$t t-\mathbf{1 b}$ & 0.42 & -13.97 & 14.39 & -0.69 & -0.83 & 1.93 & -533.95 & -4303.71 \\
\hline$c c-\mathbf{2 b}$ & 0.00 & 0.00 & 0.00 & 0.00 & 0.00 & 0.00 & 320.31 & -4424.92 \\
\hline$c t-\mathbf{2} \mathbf{b}$ & 1.06 & -10.22 & 11.28 & 0.09 & -0.01 & 0.99 & 328.07 & -4421.40 \\
\hline$t t-\mathbf{2 b}$ & 2.23 & -19.11 & 21.34 & -1.94 & 1.53 & 2.64 & 334.29 & -4417.56 \\
\hline$c c-\mathbf{3 b}$ & 0.00 & 0.00 & 0.00 & 0.00 & 0.00 & 0.00 & 204.81 & -4329.54 \\
\hline$c t-\mathbf{3 b}$ & 1.41 & -10.54 & 11.95 & 0.18 & -0.45 & 1.69 & 213.41 & -4326.19 \\
\hline$t t-\mathbf{3 b}$ & 3.18 & -22.85 & 26.03 & -1.55 & 0.52 & 4.20 & 223.98 & -4322.68 \\
\hline$c c-\mathbf{4 b}$ & 0.00 & 0.00 & 0.00 & 0.00 & 0.00 & 0.00 & -485.58 & -4713.31 \\
\hline$c t-\mathbf{4 b}$ & 4.16 & 7.80 & -3.63 & -3.11 & 5.79 & 1.48 & -487.26 & -4715.25 \\
\hline$t t-\mathbf{4 b}$ & 9.67 & -5.10 & 14.77 & -9.13 & 14.83 & 3.98 & -466.69 & -4717.42 \\
\hline$c c-\mathbf{5 b}$ & 0.00 & 0.00 & 0.00 & 0.00 & 0.00 & 0.00 & -350.90 & -5893.21 \\
\hline$c t-\mathbf{5} \mathbf{b}$ & 3.14 & 8.17 & -5.02 & -1.30 & 3.21 & 1.23 & -355.36 & -5893.78 \\
\hline$t t-\mathbf{5 b}$ & 4.88 & 12.91 & -8.02 & -3.95 & 6.36 & 2.48 & -357.72 & -5894.41 \\
\hline
\end{tabular}

The IQA quantities are explained in the text. All values in $\mathrm{kcal} / \mathrm{mol}$ intraatomic counterpart, but the differences between the $E_{\text {elst }}^{\text {inter }}$ values for the conformers of each compound are close to the differences between the values of the intraatomic electrostatic component. The same is valid for $E_{\mathrm{xc}}^{\mathrm{inter}}$ and its intraatomic counterpart. From the values of $E_{\text {elst }}^{\text {inter }}$ the preference of the $c c$-conformation can be deduced for all the compounds except $\mathbf{4 b}$ and $\mathbf{5 b}$. For these two compounds, the preference of the $c c$-conformation is recovered after the inclusion of the intraatomic electrostatic component, as it can be evidenced by the $\Delta E_{\text {elst }}$ values for $\mathbf{4 b}$ and 5b. Interestingly, the positive values of $E_{\mathrm{elst}}^{\text {inter }}$ are detected for $\mathbf{2} \mathbf{b}$ and $\mathbf{3 b}$, which indicates that the interatomic electrostatic interaction destabilizes the conformers of $\mathbf{2 b}$ and $3 \mathbf{b}$. Of the $E_{\mathrm{elst}}^{\text {inter }}$ and $E_{\mathrm{xc}}^{\text {inter }}$ components, the latter contributes the main share to the interatomic stabilization $E^{\text {inter }}$ (the percentage of $E_{\mathrm{xc}}^{\text {inter }}$ in $E^{\text {inter }}$ always far exceeds $80 \%)$. There is no single regularity in the values of $E_{\mathrm{xc}}^{\text {inter }}$ for all the investigated compounds. However, the combination of the intra- and interatomic exchange-correlation components yields the $\Delta E_{\mathrm{xc}}$ values that perfectly mimic the trends in $\Delta E$. The values of $E_{\mathrm{xc}}^{\text {inter }}$ are usually most negative for the $c c$-conformation, which is in line with the significant $\pi$-conjugation expected for this conformation. The $E_{\mathrm{xc}}^{\text {inter }}$ component is regarded as an energetic signature of 
electron delocalization, and its values indeed reflect the increasing $\pi$-conjugative interactions while going from the $t t$-conformation to the $c t$-conformation and further to the $c c$-conformation. The NBO and IQA energetic quantities evaluating the electron delocalization effect in the conformers of the investigated compounds seem to be closely related to one another (the coefficient of determination for the linear regression between $E_{\mathrm{xc}}^{\text {inter }}$ and $E^{\mathrm{NL}}$ for all conformers amounts to 0.87 ).

To end up this section, the IQA results confirm that the classical electrostatic effects contribute significantly to the determination of the preference and ordering of the investigated conformers, but the comprehensive explanation of the conformational behavior of all the investigated compounds indisputably requires the combination of the classical electrostatic energy component with the quantum mechanical, exchange-correlation energy component. The latter component includes the effects associated with electron delocalization.

\section{Conclusions}

In this work, the conformational behavior of five diheteroaryl ketones 1a-5a and the corresponding thioketones $\mathbf{1 b}-$ 5b has been established using quantum chemical WFT and DFT methods. The intramolecular energetic effects governing the conformational behavior of these compounds have been studied by means of the NBO and IQA methods. The conformational isomerism in the molecules of the investigated compounds stems from the possibility of rotation about two $\mathrm{C}-\mathrm{C}$ bonds linking the $\mathrm{C}=\mathrm{Y}$ group with the heteroaryl substituents. The results presented in this work lead to the following findings.

1. The molecules of the investigated diheteroaryl ketones and thioketones can exist in three conformations, denoted here as $c c, c t$ and $t t$ in order to indicate the spatial arrangement of the heteroatoms with respect to the $\mathrm{Y}$ atom. The overwhelming majority of the conformers found for the investigated compounds exhibit a non-planar geometry, with their heteroaryl substituents leaned outward in the opposite directions. The picture of the conformational behavior for all ten compounds is not uniform. The $c t$ conformation is most energetically favorable for $\mathbf{1 a}$ and $\mathbf{1 b}$, and the energetic stability of three conformations in the two compounds decreases in the sequence $c t>t t>c c$. In contrast to the two compounds, the remaining diheteroaryl ketones and thioketones order their conformers relative to the decreasing energetic stability as $c c>c t>t t$. Thus, the $c c$-conformation is designated as the preferred one for $\mathbf{2 a -}$ $\mathbf{5 a}$ and $\mathbf{2 b - 5 b}$.
2. The differences in energy between the individual conformers of each investigated compound span a range of several $\mathrm{kcal} / \mathrm{mol}$. The calculated energetic profiles for the interconversion between the conformations of $\mathbf{2 a}, \mathbf{2} \mathbf{b}, \mathbf{4 a}$ and $\mathbf{4 b}$ show that the resulting energy barriers for $\mathbf{2 a}$ and 2b are much smaller than those of $\mathbf{4 a}$ and $\mathbf{4 b}$. Thus, the rotation of the heteroaryl substituents in the molecules of 4a, 4b, 5a and $\mathbf{5 b}$ seems to be rather restricted and the remaining compounds are more flexible in their conformational interconversions. Furthermore, the rotation of the heteroaryl fragments in the thioketones turns out to be hindered to a greater extent than it is in the corresponding ketones.

3. The results of the NBO and IQA analyses clearly point out that the electrostatic effects are not solely responsible for the preference and ordering of the conformers. For each compound, its preferred conformer is heavily destabilized by either the steric repulsion (from the NBO perspective) or the kinetic energy component (from the IQA perspective). Such an effect is compensated totally or at least to a great extent by the stabilization resulting from either donor-acceptor delocalizing interactions (from the NBO perspective) or the exchange-correlation energy component (from the IQA perspective). It proves the importance of the energetic effect associated with electron delocalization in governing the conformational behavior of the investigated compounds.

Acknowledgments The calculations using TURBOMOLE and GAUSSIAN were carried out in the Academic Computer Center CYFRONET of the AGH University of Science and Technology in Cracow. The calculations using NBO were performed in Wroclaw Centre for Networking and Supercomputing. This work was also partially supported by PL-Grid Infrastructure. One of the authors (S.D.) thanks the National Science Center (Cracow, Poland) for financial support within the Project Maestro-3, Dec-2012/06/A/ST-5/00219.

Open Access This article is distributed under the terms of the Creative Commons Attribution 4.0 International License (http://crea tivecommons.org/licenses/by/4.0/), which permits unrestricted use, distribution, and reproduction in any medium, provided you give appropriate credit to the original author(s) and the source, provide a link to the Creative Commons license, and indicate if changes were made.

\section{References}

1. McNaught AD, Wilkinson A (1997) IUPAC. Compendium of chemical terminology. Blackwell, Oxford

2. Nic M, Jirat J, Kosata B (2014) XML version of the IUPAC compendium of chemical terminology. http://goldbook.iupac.org

3. Satoh H, Manabe S (2013) Design of chemical glycosyl donors: does changing ring conformation influence selectivity/reactivity? Chem Soc Rev 42:4297-4309 
4. Zhang F, Gotz G, Mena-Osteritz E, Weil M, Sarkar B, Kaim W, Bauerle P (2011) Molecular and electronic structure of cyclo[10]thiophene in various oxidation states: polaron pair vs. bipolaron. Chem Sci 2:781-784

5. Biswas S, Kinbara K, Niwa T, Taguchi H, Ishii N, Watanabe S, Miyata K, Kataoka K, Aida T (2013) Biomolecular robotics for chemomechanically driven guest delivery fuelled by intracellular ATP. Nat Chem 5:613-620

6. Khlebnikov AF, Novikov MS, Golovkina MV, Petrovskii PP, Konev AS, Yufit DS, Stoeckli-Evans H (2011) An efficient approach to azirino and pyrrolo-fused dibenzazepines. Conformations of substituted dibenzo[c,f]pyrrolo[1,2-a]azepines. Org Biomol Chem 9:3886-3895

7. Puchnin K, Cheshkov D, Zaikin P, Vatsouro I, Kovalev V (2013) Tuning conformations of calix[4]tubes by weak intramolecular interactions. New J Chem 37:416-424

8. Brunner H, Tsuno T, Bodensteiner M (2014) Control of the conformation of M-prophos chelate rings by $\mathrm{CH} / \pi$ interactions. Organometallics 33:2257-2265

9. Mlostoń G, Urbaniak K, Gębicki K, Grzelak P, Heimgartner H (2014) Hetaryl thioketones: synthesis and selected reactions. Heteroatom Chem 25:548-555

10. Lai Cheng C, John IG, Ritchie GLD, Gore PH, Farnell L (1975) Conformations of some 2-substituted furan and thiophen carbonyl compounds. J Chem Soc Perkin Trans 2:744-751

11. Lumbroso H, Liégeois C, Andrieu CG (1985) Preferred conformations of pivalophenone, (2-pivaloyl)- and (2-aroyl)-furans, (2pivaloyl)- and (2-aroyl)-thiophens, (2-pivaloyl)- and (2-benzoyl)selenophen, and their sulphur analogues. Z Naturforsch 40a: 1338-1348

12. Lumbroso H, Liégeois C, Pappalardo GC, Andrieu CG (1984) A dipole moment study of 2-benzoylpyrroles, di-(2-pyrryl)ketones and their sulphur analogues. J Mol Struct 112:85-99

13. Benassi R, Folli U, Larossi D, Schenetti L, Taddei F, Musatti A, Nardelli M (1989) Conformational analysis of organic carbonyl compounds. Part 11. Conformational properties of difuryl, dithienyl, and furyl thienyl ketones studied by X-ray crystallography, N.M.R. lanthanide-induced shifts and ab initio MO calculations. J Chem Soc Perkin Trans 2:1741-1751

14. Becker RS, Favaro G, Poggi G, Romani A (1995) Photophysical properties of some thienyl ketones: an experimental and theoretical study. J Phys Chem 99:1410-1417

15. Distefano G, de Palo M, Dal Colle M, Guerra M (1998) Ab initio determination of the geometric structure of oligo-2-thienyl ketones. J Mol Struct (Theochem) 455:131-140

16. Dal Colle M, Cova C, Distefano G, Jones D, Modelli A, Comisso N (1999) Determination of the electronic structure of oligo(2thienyl ketones) and extrapolation to poly(thienylene ketone). J Phys Chem A 103:2828-2835

17. da Silva Miranda F, Gava Menezes F, Vicente J, Bortoluzzi AJ, Zucco C, Neves A, Sanches Gonçalves N (2009) Bis-(1H-benzimidazol-2-yl)-methanone: new preparation method, crystal structure, vibrational spectroscopy and DFT calculations. J Mol Struct 938:1-9

18. Wang H, Wang L, Shen S, Zhang W, Li M, Du L, Zheng X, Phillips DL (2012) Effects of hydrogen bond and solvent polarity on the $\mathrm{C}=\mathrm{O}$ stretching of bis(2-thienyl)ketone in solution. J Chem Phys 136:124509

19. Latelli N, Ouddai N, Arotçaréna M, Chaumont P, Mignon P, Chermette H (2014) Mechanism of addition-fragmentation reaction of thiocarbonyls compounds in free radical polymerization. A DFT study. Comput Theor Chem 1027:39-45

20. Møller C, Plesset MS (1934) Note on an approximation treatment for many-electron systems. Phys Rev 46:618-622

21. Cremer D (1998) Møller-Plesset perturbation theory. In: Schleyer PvR, Allinger NL, Clark T, Gasteiger J, Kollman PA, Schaefer
HF III, Schreiner PR (eds) Encyclopedia of computational chemistry. Wiley, Chichester, pp 1706-1735

22. Becke AD (1993) Density-functional thermochemistry. III. The role of exact exchange. J Chem Phys 98:5648-5652

23. Vosko SH, Wilk L, Nusair M (1980) Accurate spin-dependent electron liquid correlation energies for local spin density calculations: a critical analysis. Can J Phys 58:1200-1211

24. Lee C, Yang W, Parr RG (1988) Development of the ColleSalvetti correlation-energy formula into a functional of the electron density. Phys Rev B 37:785-789

25. Weigend F, Ahlrichs R (2005) Balanced basis sets of split valence, triple zeta valence and quadruple zeta valence quality for $\mathrm{H}$ to $\mathrm{Rn}$ : design and assessment of accuracy. Phys Chem Chem Phys 7:3297-3305

26. Grimme S (2006) Semiempirical GGA-type density functional constructed with a long-range dispersion correction. J Comput Chem 27:1787-1799

27. Grimme S, Antony J, Ehrlich S, Krieg H (2010) A consistent and accurate ab initio parametrization of density functional dispersion correction (DFT-D) for the 94 elements H-Pu. J Chem Phys 132:154104

28. Grimme S, Ehrlich S, Goerigk L (2011) Effect of the damping function in dispersion corrected density functional theory. J Comput Chem 32:1456-1465

29. Grimme S (2003) Improved second-order Møller-Plesset perturbation theory by separate scaling of parallel- and antiparallelspin pair correlation energies. J Chem Phys 118:9095-9102

30. Gauss J (1998) Coupled-cluster theory. In: Schleyer PvR, Allinger NL, Clark T, Gasteiger J, Kollman PA, Schaefer HF III, Schreiner PR (eds) Encyclopedia of computational chemistry. Wiley, Chichester, pp 615-636

31. Weigend F, Häser M (1997) RI-MP2: first derivatives and global consistency. Theor Chem Acc 97:331-340

32. Ahlrichs R, Armbruster MK, Bachorz RA, Bär M, Baron HP, Bauernschmitt R, Bischoff FA, Böcker S, Crawford N, Deglmann P, Della Sala F, Diedenhofen M, Ehrig M, Eichkorn K, Elliott S, Friese D, Furche F, Glöß A, Haase F, Häser M, Hättig C, Hellweg A, Höfener S, Horn H, Huber C, Huniar U, Kattannek M, Klopper W, Köhn A, Kölmel C, Kollwitz M, May K, Nava P, Ochsenfeld C, Öhm H, Pabst M, Patzelt H, Rappoport D, Rubner O, Schäfer A, Schneider U, Sierka M, Tew DP, Treutler O, Unterreiner B, von Arnim M, Weigend F, Weis P, Weiss H, Winter N (2014) TURBOMOLE 6.6, a development of University of Karlsruhe and Forschungszentrum Karlsruhe GmbH, 1989-2007, TURBOMOLE GmbH, since 2007. http://www.turbomole.com

33. Reed AE, Curtiss LA, Weinhold F (1988) Intermolecular interactions from a natural bond orbital, donor-acceptor viewpoint. Chem Rev 88:899-926

34. Blanco MA, Pendás MA, Francisco E (2005) Interacting quantum atoms: a correlated energy decomposition scheme based on the quantum theory of atoms in molecules. J Chem Theory Comput 1:1096-1109

35. Glendening ED, Badenhoop JK, Reed AE, Carpenter JE, Bohmann JA, Morales CM, Landis CR, Weinhold F (2013) NBO 6.0. Theoretical Chemistry Institute, University of Wisconsin, Madison

36. Keith TA (2014) AIMAll (Version 14.06.21), TK Gristmill Software, Overland Park KS, USA

37. Frisch MJ, Trucks GW, Schlegel HB, Scuseria GE, Robb MA, Cheeseman JR, Scalmani G, Barone V, Mennucci B, Petersson GA, Nakatsuji H, Caricato M, Li X, Hratchian HP, Izmaylov AF, Bloino J, Zheng G, Sonnenberg JL, Hada M, Ehara M, Toyota K, Fukuda R, Hasegawa J, Ishida M, Nakajima T, Honda Y, Kitao O, Nakai H, Vreven T, Montgomery JA Jr, Peralta JE, Ogliaro F, Bearpark M, Heyd JJ, Brothers E, Kudin KN, Staroverov VN, Keith T, Kobayashi R, Normand J, Raghavachari K, Rendell A, 
Burant JC, Iyengar SS, Tomasi J, Cossi M, Rega N, Millam JM, Klene M, Knox JE, Cross JB, Bakken V, Adamo C, Jaramillo J, Gomperts R, Stratmann RE, Yazyev O, Austin AJ, Cammi R, Pomelli C, Ochterski JW, Martin RL, Morokuma K, Zakrzewski VG, Voth GA, Salvador P, Dannenberg JJ, Dapprich S, Daniels AD, Farkas O, Foresman JB, Ortiz JV, Cioslowski J, Fox DJ (2013) Gaussian 09 D.01, Gaussian, Inc., Wallingford, CT

38. Dubis AT, Domagała M, Grabowski SJ (2010) Spectroscopic and theoretical studies on some new pyrrol-2-yl-chloromethyl ketones. New J Chem 34:556-566

39. Dubis AT, Grabowski SJ (2001) Infrared spectroscopic and theoretical ab initio studies on conformational isomers of methyl pyrrole-2-carboxylate. J Mol Struct 562:107-117

40. Dubis AT, Grabowski SJ (2002) Spectroscopic and theoretical studies on the monomeric and dimeric forms of methyl pyrrole-2carboxylate. New J Chem 26:165-169

41. Dubis AT, Grabowski SJ, Romanowska DB, Misiaszek T, Leszczynski J (2002) Pyrrole-2-carboxylic acid and its dimers: molecular structures and vibrational spectrum. J Phys Chem A 106:10613-10621

42. Dubis AT, Grabowski SJ (2003) Infrared, density-functional theory, and atoms in molecules method studies on conformers of some 2-substituted 1H-pyrroles. J Phys Chem A 107:8723-8729

43. Grabowski SJ, Dubis AT, Martynowski D, Główka M, Palusiak M, Leszczynski J (2004) Crystal and molecular structure of pyrrole-2carboxylic acid; $\pi$-electron delocalization of its dimers-DFT and MP2 calculations. J Phys Chem A 108:5815-5822

44. Grabowski SJ, Dubis AT, Palusiak M, Leszczynski J (2006) Heteronuclear intermolecular resonance-assisted hydrogen bonds. The structure of pyrrole-2-carboxamide (PyCa). J Phys Chem B 110:5875-5882

45. Santos AFLOM, Ribeiro Da Silva MAV (2009) Experimental and computational study on the molecular energetics of 2-pyrrolecarboxylic acid and 1-methyl-2-pyrrolecarboxylic acid. J Phys Chem A 113:9741-9750

46. Neese F, Valeev EF (2011) Revisiting the atomic natural orbital approach for basis sets: robust systematic basis sets for explicitly correlated and conventional correlated ab initio methods? J Chem Theory Comput 7:33-43

47. Gruzman D, Karton A, Martin JML (2009) Performance of $\mathrm{ab}$ initio and density functional methods for conformational equilibria of $\mathrm{C}_{n} \mathrm{H}_{2 n+2}$ alkane isomers $(n=4-8)$. J Phys Chem $\mathrm{A}$ 113:11974-11983

48. Marianski M, Asensio A, Dannenberg JJ (2012) Comparison of some dispersion-corrected and traditional functionals as applied to peptides and conformations of cyclohexane derivatives. J Chem Phys 137:044109

49. Grimme S, Mück-Lichtenfeld C (2008) Calculation of conformational energies and optical rotation of the most simple chiral alkane. Chirality 20:1009-1015

50. Fogueri UR, Kozuch S, Karton A, Martin JML (2013) The melatonin conformer space: benchmark and assessment of wave function and DFT methods for a paradigmatic biological and pharmacological molecule. J Phys Chem A 117:2269-2277

51. Schofield DP, Jordan KD (2012) Determination of conformational preferences in biomolecule mimics with localized orbital coupled cluster methods. AIP Conf Proc 1504:957-960
52. Matczak P, Łukomska M (2014) Assessment of various density functionals for intermolecular $\mathrm{N} \rightarrow \mathrm{Sn}$ interactions: the test case of trimethyltin cyanide dimer. Comput Theor Chem 1036:31-43

53. Matczak $P$ (2015) Theoretical investigation of the $\mathrm{N} \rightarrow \mathrm{Sn}$ coordination in $\left(\mathrm{Me}_{3} \mathrm{SnCN}\right)_{2}$. Struct Chem 26:301-318

54. Matczak P, Wojtulewski S (2015) Performance of Møller-Plesset second-order perturbation theory and density functional theory in predicting the interaction between stannylenes and aromatic molecules. J Mol Model 21:41

55. Guerra M, Pedulli GF, Tiecco M, Martelli G (1974) Conformational isomers and rotational barriers in the ketyl radicals of thiophen and thienothiophens. J Chem Soc Perkin Trans 2:562-567

56. Kus N, Sharma A, Reva I, Lapinski L, Fausto R (2010) Thermal and photoinduced control of relative populations of 4-methoxybenzaldehyde (p-anisaldehyde) conformers. J Phys Chem A 114:7716-7724

57. Dubis AT (2014) Conformational preferences of 2-acylpyrroles in light of FT-IR and DFT studies. Phys Chem Biophys 4: 1000155

58. Ashisha H, Ramasamia P (2008) Rotational barrier and thermodynamical parameters of furfural, thiofurfural, and selenofurfural in the gas and solution phases: theoretical study based on density functional theory method. Mol Phys 106:175-185

59. Abdallah HH, Ramasami P (2009) First principle study of the anti- and syn-conformers of thiophene-2-carbonyl fluoride and selenophene-2-carbonyl fluoride in the gas and solution phases. In: Allen G, Nabrzyski J, Seidel E, van Albada GD, Dongarra J, Sloot PMA (eds) Computational science-ICCS 2009. Springer, Baton Rouge

60. Kvapilová H, Eigner V, Hoskovcová I, Tobrman T, Čejka J, Záliš S (2014) Structural flexibility of 2-hetaryl chromium aminocarbene complexes: experimental and theoretical evidence. Inorg Chim Acta 421:439-445

61. Benassi R, Folli U, Schenetti L, Taddei F (1987) Conformational analysis of organic carbonyl compounds. Part 6. Theoretical examination of the conformational properties (ground and transition states) and solvent effects on 2-formyl-furan, -thiophene, and -pyridine. J Chem Soc Perkin Trans 2:961-968

62. Martınez-Mayorga K, Juaristi E, Cuevas G (2004) Manifestation of stereoelectronic effects on the calculated carbon-hydrogen bond lengths and one-bond ${ }^{1} \mathrm{~J}_{\mathrm{C}-\mathrm{H}}$ NMR coupling constants. Relative acceptor ability of the carbonyl $(\mathrm{C}=\mathrm{O})$, thiocarbonyl $(\mathrm{C}=\mathrm{S})$, and methylidene $\left(\mathrm{C}=\mathrm{CH}_{2}\right)$ groups toward $\mathrm{C}-\mathrm{H}$ donor bonds. J Org Chem 69:7266-7276

63. Ducati LC, Freitas MP, Tormena CF, Rittner R (2008) The case of intramolecular hydrogen bonding, hyperconjugation and classical effects on the conformational isomerism of substituted carbonyl and thiocarbonyl compounds. J Mol Struct THEOCHEM 851:147-157

64. Coelho JV, de Freitas MP, Ramalho TC (2008) The role of carbonyl and thiocarbonyl groups in the conformational isomerism of haloacetones and halothioacetones. Struct Chem 19:671-677

65. Badenhoop JK, Weinhold F (1997) Natural bond orbital analysis of steric interactions. J Chem Phys 107:5406-5421

66. Weinhold F, Landis CR (2012) Discovering chemistry with natural bond orbitals. Wiley, Hoboken 